\title{
Research Trends into Support for Families Coping with Dementia in Japan
}

\author{
Motoko Kita $^{1} \&$ Reiko Yoshida ${ }^{2}$ \\ ${ }^{1}$ School of Nursing, The Jikei University, Tokyo, Japan \\ ${ }^{2}$ School of Human Care, Teikyo Heisei University, Toshima, Tokyo, Japan \\ Correspondence: Motoko Kita, School of Nursing, The Jikei University, 8-3-1 Kokuryocho, Chofu, Tokyo \\ 182-8570, Japan. Tel: 81-3-3480-1151 ext 2890.
}

Received: March 15, 2017

Accepted: April 3, 2017

Online Published: April 24, 2017

doi:10.20849/ijsn.v2i1.144

URL: https://doi.org/10.20849/ijsn.v2i1.144

\begin{abstract}
In Japan, there is a growing need for family support of elderly patients with dementia because the number of sufferers is expected to increase over coming years. We conducted a review of 92 studies into the support provided to the families of patients with dementia in Japan. They were reviewed by care setting, study focus, and study design. Most studies were in home settings, followed by hospital settings, with the fewest in long-term care facilities. A wide range and quality of studies were performed in home settings, including quantitative descriptive and interventional studies; however, qualitative descriptive studies and case studies predominated. We identified a need to perform additional studies to verify support programs at home. Concerning family support in hospitals, studies were mainly performed in relation to early diagnosis of dementia and early discharge from hospital, and we observed a clear need to investigate the development of new support programs. Finally, although the need for family support is estimated to be high in long-term care facilities, we found only a few studies investigating this issue. In particular, more studies are needed on the topic of end-of-life care. To offer support that meets the needs of families in various care settings, there is an urgent need to accumulate evidence about patients and their families in each setting.
\end{abstract}

Keywords: family nursing, dementia, family support, review

\section{Introduction}

\subsection{The Scale of the Problem Posed by Dementia}

The growth in the size of Japan's elderly population is much faster than that of any other country. In 1970, the elderly accounted for only $7.2 \%$ of the total population of Japan, but by 1994 , this had almost doubled to $14.1 \%$. Whereas this increase took only 24 years in Japan, comparison with other countries with large elderly populations show marked differences, with comparable increases taking 62 years in Italy, 85 years in Sweden, and 115 years in France. These clearly highlight the rapid progress of demographic aging in Japan. In 2014, there were 31.9 million elderly people in Japan, which accounted for $25.1 \%$ of the population (Soumushyoutoukeikyoku [Statistics Japan], 2014).

Against this backdrop, the prevalence of dementia is also increasing rapidly. In August 2012, the Health and Welfare Bureau for the Elderly (Japanese Ministry of Health, Labour and Welfare, 2012) published a report indicating that the estimated number of elderly persons with dementia could increase to as much as 4.70 million by 2025 . If these trends hold true, the disease will then be present in about $13 \%$ of the elderly population, affecting more than one in ten elderly people (Kouseiroudousyou [Ministry of Health, Labour and Welfare], 2014)

\subsection{The Importance of Ensuring Proper Family Support}

Due to this increase in the number of people with dementia, there is an increasingly urgent need to develop and provide high-quality support, not only for patients with dementia but also for their families. In response to this problem, the Japanese government formulated a "Five-year Plan for Promotion of Measures against Dementia" (Ministry of Health, Labour and Welfare, 2014). Enhancement of support for the families of elderly people with dementia was included in this plan. A report from the Ministry of Health, Labor and Welfare (2010) indicated that approximately 1.4 million elderly people with dementia were living at home, 1.01 million were living in 
long-term care facilities, and 0.38 million were living in medical institutions (Kouseiroudousyou [Ministry of Health, Labour and Welfare], 2014).

The problems of the families of patients with dementia are becoming better recognized, not only for those caring for patients at home but also for those caring for patients in long-term care facilities and medical institutions. These problems are distinct from those faced by the caregivers of elderly people without dementia, because dementia is also associated with memory loss and recognized behavioral and psychological symptoms, such as wandering and irritability. Therefore, families have unique dementia-specific problems that differ by care setting, and we must recognize these as differing needs when seeking to provide high-quality support for patients and families who are in the midst of dealing with dementia.

\section{$1.3 \mathrm{Aim}$}

In this review, we aimed to obtain a general overview of the studies concerning support for the families of patients with dementia in Japan. We also planned to clarify the trends and issues raised by such studies, as stratified by care setting, study focus, and study design.

\section{Method}

\subsection{Design}

We conducted a literature review using the database of the Japan Medical Abstracts Society (ICHUSHI), and reviewed articles identified on support for the families of elderly people with dementia. The ICHUSHI database contains information about articles published in approximately 5000 medical, dental, pharmaceutical, nursing, and related periodicals in Japan.

\subsection{Search Terms and Methods}

A search was performed for original articles published from January in 2000 to December in 2016 using the key words "dementia" AND "family support" OR "family care." All identified articles were reviewed manually. Those with content focusing on support for the families of patients with dementia were included in the final review. When analyzing the studies, we focused on three aspects: 1) the care setting, 2) the study focus, and 3) the study design.

\section{Results}

A total of 159 related studies were identified. Among these, 92 focused on support for the families of patients with dementia, and are summarized in Table 1. As shown in the table, 54 studies (59\%) focused on home settings, $25(27 \%)$ on medical institutions, and $13(14 \%)$ on long-term care facilities. The studies under review conducted from 1998 to 2015.

Table 1. Identified studies by care setting and design

\begin{tabular}{lccc}
\hline \multicolumn{1}{c}{ Study design } & Home care setting & Medical setting & Long-term care setting \\
\hline Qualitative descriptive study & 19 & 8 & 8 \\
Case study & 15 & 10 & 1 \\
Quantitative descriptive study & 7 & 2 & 4 \\
Interventional study & 7 & 2 & 0 \\
Correlational study & 3 & 2 & 0 \\
Questionnaire development & 1 & 0 & 0 \\
Literature review & 2 & 1 & 0 \\
\hline Total & 54 & 25 & 13 \\
\hline
\end{tabular}

Description: this table summarizes the numbers of studies on support for the families of people with dementia in Japan by study design and care setting $(\mathrm{N}=92)$ 


\subsection{Research Design and Study Focus for Support in Home Care Settings}

Analysis of the research design of studies on home care revealed a wide range of studies. Although these included quantitative descriptive studies and interventional studies, most were qualitative descriptive studies or case studies.

The case studies tended to analyze single or multiple difficult cases by retrospective assessment of family support issues and it was shown that the family's lack of understanding of dementia leads to a negative response to elderly people with dementia, which has led to the deterioration of family relations; however, this relationship could be improved by the involvement of nursing (Tanaka, Akagi, Takushima, \& Yamaguchi, 2007) (Iwaki, Tamekuni, Maekawa, \& Sasaki, 2002).

The qualitative descriptive studies investigated various issues, which are clarified. Although the family caregivers try to rectify behaviors of elderly people with dementia that they cannot take their eyes off, that attempt worsens their relationship with the elderly, which in turn allows families to realize the sense of self-reproach and the pointlessness of their trial. Subsequently, it changes the family caregiver to allow the behavior of the elderly that does not cause inconvenience to other people (Watanabe \& Watanabe, 2015) (Suzuki, Matsuda, \& Sakurai, 2015). The Elderly Dementia Patient Family Association provides emotional support in relation to others and provides opportunities to the family caregiver to obtain information, but its significance depends on the caregiver's view of life (Omori, Kimura, Sano, Mine, \& Matsumoto, 2007) (Matsumura \& Kawagoe, 2001). Families continue long-term care while they reorganize the family livelihoods, thereby deepening their ties with the elderly and acquiring new learning (Tanaka, Fukuhara, Shimamoto, Takata, \& Ikezoe, 2012) (Nishiyama, 2005). Male family caregivers find it difficult to deal with people with dementia, but they also feel anxious about housework, embarrassment to neighborhoods, social isolation, and their own health (Nagasawa, Yamamura, \& Iwashimizu, 2015) (Matsumoto, Osono, \& Morikawa, 2014). These have studies promoted a multifaceted understanding of the families of patients with dementia.

Quantitative descriptive studies show that the stress coping patterns of family caregivers of the elderly with dementia have features such as watching over, lowering the expectation value, and devising preventive measures (Nagai, 2011); male family caregivers have a high ability to cope with health problems and utilize social resources, but their relationship adjustment ability is low (Kawano, Hirano, Torii, \& Hishiyama, 2008); the service provider related to the elderly with dementia collects the information about family as important information (Yamamura, Lee, \& Kase, 2012).

In the interventional studies, the effects of different family support programs were verified. As a result, it was demonstrated that the support intervention program, which consists of providing knowledge on dementia, providing information about the care condition of the elderly in day care services, and exchanging information among family caregivers (Kamijou, Nakamura, Nto, \& Ogihara, 2009), and the intervention program regarding structured stress management, including relaxation training (Hosaka \& Sugiyama, 2003), could improve the caregivers' burden or the behavioral and psychological symptoms of dementia of the elderly.

In addition, there were several correlation studies that investigated the relationships between family caregivers' burdens and either family health-related quality of life (Fujiwara, Yamaguchi, Koike, Hirao \& Kamijyou, 2010), family function (Fugiwara, Kamijyou, Komatsu, Edo, \& Suganuma, 2011), or the methods used for coping with the behavioral and psychological symptoms of dementia (Kusumoto, Yokokawa, Ikeda, Suzuki, \& Kondou, 2007). These studies show that there is a relationship between family caregivers' burden and family function or their physical and mental health; the lower understanding of the family caregiver about how to cope with the patients' behavioral and psychological symptoms of dementia leads to a higher sense of the caregivers' burden .

\subsection{Research Design and Study Focus for Support in Medical Care Settings}

In total, 18 of the 25 studies conducted at medical institutions were case studies or qualitative descriptive studies. The research tended to focus on the influence of early diagnosis of dementia on families (Ikehata et al., 2009), the status of families during hospitalization (Taniguchi, 2003) (Sugiyama, Yuasa, \& Takahashi, 2009), the process of building trust with families (Maeshiro, 2010), the support offered during discharge (Hatada, 2011) (Ojima \& Kimura, 2011), the support given to help families make surrogate treatment decisions (Ooki, Ogata, \& Matsuo, 2015), and the difficulties faced by nurses when coping with families (Matsuo, 2011).

These studies demonstrate that nurses have difficulty when dealing with families that cannot understand the condition of patients with dementia during hospitalization (Matsuo, 2011), but the diagnosis of dementia and the behavioral and psychological symptoms of the elderly are unacceptable for family members, and it takes time to understand (Taniguchi, 2003) (Sugiyama, Yuasa, \& Takahashi, 2009). While the care burden of family caregivers 
is reduced during the hospitalization period, family members have a different sense of burden when deciding the place to live for the elderly after the discharge, complaints and anxiety about hospital care and treatment, anxiety about deterioration of the patient's physical symptoms, burden regarding visiting, and restraints accompanying hospitalization (Taniguchi, 2003) (Sugiyama, Yuasa, \& Takahashi, 2009). When family members cannot understand the patients' behavioral and psychological symptoms of dementia, the relationships with the elderly tend to worsen, and it is important that nurses understand the feelings of the families and deepen their understanding of dementia (Maeshiro, 2010).

In addition, it is shown that in hospital discharge support, nurses understand that families are puzzled by the fact that their family member has developed dementia; have an attitude to wait and provide emotional support by listening to their story so that the families can take the care role; as well as provide the information about care techniques for the elderly persons with dementia, response to accidents, and utilization of social resources after discharge to their home (Ojima \& Kimura, 2011). With such support, an elderly person with dementia could be able to be discharged to his/her home (Hatada, 2011).

Furthermore, when families cannot understand the characteristics of dementia and the course followed, it is difficult for the families to forecast the situation after choosing the treatment even in surrogate decision making in case of medical treatment, and the families suffer from anxiety (Ooki, Ogata, \& Matsuo, 2015).

\subsection{Research Design and Study Focus for Support in Long-term Care Settings}

Most of the 11 studies on family support in long-term care facilities were qualitative or quantitative descriptive studies, and they focused on end-of-life care. The needs of families engaged in such care (Kawakita, 2015) (Tanaka, Ishii, \& Matsumoto, 2011) or the process of supporting decision-making (Futagami, Watanabe, \& Chiba, 2010) were explored in several studies. As a result, it is clarified that families feel a deepened relationship with the elderly by being involved in terminal care, but through the process that leads to the death of elderly people with dementia, families also have stress during the care and have anxiety of whether surrogate decision making in medical practice accompanying life extension of the elderly reflects the intention of the elderly.

Investigations were also performed into the actual state of family support by facilities (Morioka, 2000), the level of satisfaction of the families with facilities (Nakajima, Nagata, \& Hirabayashi, 2006), and the experience of families on admission of their elderly relatives to facilities (Kobayashi, 2004). These studies show that the duration of stay of elderly people with dementia at the institution is longer than that of those without dementia, and family support is insufficient. On the other hand, families have a high satisfaction level for living and services at facilities and have expectations for the elderly to be able to live their own life; however, there is still need for family support for the elderly as they go out. In addition, families have anxiety about the adaptation of the elderly to the life at the institution and guilt of placing the elderly in long-term care facilities.

\section{Discussion}

This review indicates that there was a greater number of studies on support for the families of patients with dementia in home settings, and that the state of research was more advanced in this setting when compared with other care settings. According to studies in home settings, it is suggested that intervention so that families can better understand dementia is important because the lack of understanding of dementia results in the deterioration of family relations and quality of family care giving (Tanaka, Akagi, Takushima, \& Yamaguchi, 2007) (Iwaki, Tamekuni, Maekawa, \& Sasaki, 2002) (Watanabe \& Watanabe, 2015) (Suzuki, Matsuda, \& Sakurai, 2015). Although the research was primarily descriptive, some interventional studies had been performed to verify the effects of family support programs at home. In the studies on the effects of family support programs, various programs for reducing the burden of home care on caregivers were reviewed (Kamijou, Nakamura, Nto, \& Ogihara, 2009) (Hosaka \& Sugiyama, 2003). However, these programs are still under development, so additional verification will be needed in the future to develop more effective programs. Overall, there was clear evidence that research has focused on the burden of home care on families, but that some findings should be verified in the future.

As for studies in hospital settings, there were only a few studies, and these studies tended to focus on the socially important topics of support for early diagnosis and discharge. Indeed, these reflect the health policies promoted in Japan; equally, the focus on research into care at home reflects the focus on developing medical services to support living in local communities. Those studies indicated that even in the case of early diagnosis and discharge support, dementia and its behavioral and psychological symptoms of the elderly are unacceptable for the families (Taniguchi, 2003) (Sugiyama, Yuasa, \& Takahashi, 2009) (Ojima \& Kimura, 2011); therefore, emotional support is important for the families. Unfortunately, however, much of the research on these important topics was in the form of case studies or qualitative descriptive studies, and it has therefore been limited to 
describing the phenomena. In the future, it will be necessary to perform studies using more robust research designs to assess the status of support and to develop support methods for families coping with early diagnosis and early discharge from hospital.

We must remember that many elderly people with dementia are also admitted to long-term care facilities. One of the studies in this care setting shows that families have anxiety about the adaptation of the elderly to life at the institution and guilt of placing the elderly in long-term care facilities (Kobayashi, 2004). Because family care for these elderly patients does not cease with admission (Woods, Keady, \& Seddon, 2008), there may be a missed need to support the families of patients at these facilities. However, the smallest number of studies in this review focused on family support in long-term care facilities. Moving forward, it will be necessary to perform more studies in long-term care facilities, starting with descriptive studies that provide accurate quantitative and qualitative assessment of the present status. In these long-term care settings, research attention has often focused only on the needs and difficulties of families engaged in end-of-life care, consistent with the increased prevalence of elderly patients with dementia with a high dependence on medical care. Further studies on this particularly important subject are needed.

In conclusion, in this review, we found that family acceptance of the fact that elderly people (their family members) develop dementia and support of the elderly people based on the understandings of characteristics of dementia are important not only for the elderly but also for family relations. In addition, it is important to reduce the burden of family care giving. Therefore, it was suggested that there is a need for nursing intervention to provide knowledge on dementia and emotional support to families. The development of support programs for families and its verification are underway in the home care setting. However, if we are to offer support that meets the needs of the families of patients with dementia in different care settings, there is an urgent need to accumulate evidence using robust study designs in each setting.

\section{Acknowledgments}

This study was funded by a Grant-in-Aid for Scientific Research (C) from The Ministry of Education, Culture, Sports, Science and Technology, Japan. The funding source had no such involvement in study design; in the collection, analysis and interpretation of data; in the writing of the report; and in the decision to submit the paper for publication. The authors would like to thank Enago (www.enago.jp) for the English language review.

\section{References}

Fugiwara, K., Kamijyou, K., Komatsu, Y., Edo, A., \& Suganuma, I. (2011). Relationship between family function andburden experienced by primary caregivers of elderly persons with dementia: An investigation using the family adaptability and cohesion evaluation scale (FACESKG) developed at Kwansei Gakuin. Nishi Kyuusyuu rihabiriteisyon kenkyuu (West Kyusyu Journal of Rehabilitation Sciences), 4, 1-5.

Fujiwara, K., Yamaguchi, T., Koike, S., Hirao, K., \& Kamijyou, K. (2010). Zaitaku ninchisyou koureisya no syutaru kaigosya niokeru kaigofutankan to kenkoukanren QOL (Quality of Life) no kanren nituite (Association between caregiver burden of the main caretakers of demented elderly living at home and their health-related QOL). Igaku to seibutugaku (Medicine and Biology), 154(5), 246-252.

Futagami, M., Watanabe, M., \& Chiba, M. (2010). Experiences of Families Coping with Difficulties in Proxy Decision-making about Advance Directive for Old Persons with Dementia in Nursing Homes. Rounenkangogaku (Journal of Japan Academy of Gerontological Nursing), 14(1), 25-33.

Hatada, C. (2011). Ninchisyou kanjya no taiinshien wo toosite manandakoto: kanjya no omoi niyorisotte (Findings Learnt through Discharge Support for Dementia Patients: Understanding Patients' Feelings). Nihon seisinka kango gakkaishi (Journal of the Japanese Psychiatric Nursing Society), 54(3), 119-123.

Hosaka, T., \& Sugiyama, Y. (2003). Structured intervention in family caregivers of the demented elderly and changes in their immune function. Psychiatry and Clinical Neurosciences, 57(2), 147-151, In english. https://doi.org/10.1046/j.1440-1819.2003.01094.x

Ikehata, M., Oohashi, T., Hosoi, D., Oominato, H., Higuchi, K., Kyouda, Y., \& Kikuhara, Y. (2009). Syoki arutsuhaimaa-gata ninchisyou no soukisindan ga kazoku ni oyobosu eikyou (Effects of Early Diagnosis of Presenile Alzheimer's Disease on the Patient's Family). Nihon seisinka kango gakkaishi (Journal of the Japanese Psychiatric Nursing Society), 52(1), 116-117.

Iwaki, S., Tamekuni, Y., Maekawa, N., \& Sasaki, N. (2002). Kazoku no kankei kaizen wo hakaru tameno apuroochi (Approach for Improving Family Relationships). Nihon seisinka kango gakkaishi (Journal of the Japanese Psychiatric Nursing Society), 45(1), 99-102. 
Kamijou, K., Nakamura, T., Nto, M., \& Ogihara, Y. (2009). Deikea niokeru ninchisyou kazoku-kaigosya no 'kazokushien puroguramu' no kouka (The effectiveness of a family support program for caregivers of persons with dementia in daycare). Nihon ninchisyou kea gakkai (Journal of Japanese Society for Dementia Care, 8(3), 394-402.

Kawakita, E. (2015). Kazoku-kaigosya kara mita ninchisyou-koureisya no saigo nomukaekata niokeru uketome no jittai; kazoku-shien wo fukumeta endo-obu- raifu- kea no arikata wo mezashite (State of Accepting the Terminal Stage of Elderly Dementia Patients from the Viewpoint of Caregiver Family Members: Aiming for Ideal End-of-Life Care Including Family Support). Nihon kango-fukushigakukaishi (Journal of Japanese Society for the Study of Nursing and Social Work), 21(1), 75-89.

Kawano, E., Hirano, M., Torii, H., \& Hishiyama, Y. (2008). Dansei ga syu-kaigosya dearu kazoku heno seikaturikiryoukoujyou wo mezashita shien (Support for Families with Male Primary Caregivers: Focusing on Family Living Capacit). Kazoku kangogaku kenkyuu (Japanese Journal of Research in Family Nursing, 13(3), 150-157.

Kobayashi, K. (2004). Chiyousei-koureisya no guruupuhoumu nyuusyo nitomonau syu-kaigosya no omoito koudou no tokuchou (Characteristic Emotions and Activities of the Main Caregivers in Group Homes for the Senile Elderly). Gunma paasu gakuen tankidaigaku kiyou (Bulletin of Gunma Paz Gakuen College), 6(1), 29-39.

Kouseiroudousyou (Ministry of Health, Labour and Welfare). (2014). Ninchisyou koureisyanituite (The number of the elderly people with dementia). Retrieved December 1, 2016, from http://www.mhlw.go.jp/stf/houdou/2r9852000002iau1-att/2r9852000002iavi.pdf

Kouseiroudousyou (Ministry of Health, Labour and Welfare). (2014). Ninchisyou sesakusuishin sougou senryaku - Ninchisyou koureisya tou ni yasashii chiiki dukuri ni mukete-shin orenge plan. (Regarding the "General Dementia Countermeasure Promotion Strategy-Aiming to Create Communities Friendly to Elderly Dementia Patients [New Orange Plan]"). Retrieved December 1, 2016, from http://www.mhlw.go.jp/stf/houdou/0000072246.html

Kusumoto, Y., Yokokaw,a M., Ikeda, C., Suzuki, A., \& Kondou, F. (2007). Ninchisyou koureisya no mondaikoudou ni taisuru syu-kaigosya no taiouhouhou to kaigofutankan tono kankei (Relationship between the Method of Main Caregiver Response to Problematic Behavior by Elderly Dementia Patients and a Sense of Care Burden). Nihon kangogakkai ronbunsyuu: rounenkango (Japanese Nursing Association Collection of Papers: Geriatric Nursing), 37, 73-35.

Maeshiro, H. (2010). Taiin heno shinritekihenka wo miseru kazoku tono kakawari: kanjya-kazokukankei no hatten ni syouten wo atete (Involvement with Family Exhibiting Psychological Changes for Hospital Discharge: Focusing on Development of the Patient-Family Relationship). Nihon seisinka kango gakkaishi (Journal of the Japanese Psychiatric Nursing Society), 53(3), 71-74.

Matsumoto, K., Osono, Y., \& Morikawa, C. (2014). Ninchisyou-koureisya wo kaigo suru dansei-haiguusya no kaigo no omoi no yousou (Phases in the Feelings Regarding Care by Men who Care for an Elderly Spouse with Dementia). Nihon kango-fukushigakukaishi (Journal of Japanese Society for the Study of Nursing and Social Work), 19(2), 155-167.

Matsumura, C., \& Kawagoe, H. (2001). Meaning for Caregivers of their Participation at Self-help Groups for Families of Patients with Dementia. Seiroka kangogakkaishi (Journal of St. Luke's Society of nursing Research), 5(1), 1-9.

Matsuo, K. (2011). Ippanbyoutou nioite kangoshi ga taikenshita ninchisyoukoureisya heno taiou no konnansa (Difficulties Experienced by Nurses who Care for Elderly People with Dementia). Nihonsekijyuuji kangodaigaku kiyou (Bulletin of the Japanese Red Cross College of Nursing), 25, 103-110.

Morioka, K. (2000). Tonai roujinhokenshisetu niokeru chiyousei-roujin nitaisuru syoguu oyobikazokutou heno shien no jittai: tonai roujinhokenshisetu heno ankeitotyousa yori (State of Treatment and Support for Elderly Dementia Patients in Elderly Care Facilities in Tokyo: Based on a Questionnaire Survey of Elderly Care Facilities in Tokyo). Rounenseishinigakuzasshi (Japanese journal of geriatric psychiatry), 11(3), 309-313.

Nagai, M. (2011). Zaitaku ninchisyou koureisya no kaigosya niokeru sutoresutaisyoyousiki no kouzou (Stress-Coping Style of Caregivers for Demented Elderly at Home). Kazoku kangogaku kenkyuu (Japanese Journal of Research in Family Nursing), 16(3), 178-184. 
Nagasawa, K., Yamamura, E., \& Iwashimizu, T. (2015). Ninchisyou ni rikan shita tsuma nokaigo wosuru otto-kaigosya ga kanjiteiru konnan (Diffculty of Informal Caregiving Provided by Husbands to Dementia Patients). Kazoku kangogaku kenkyuu (Japanese Journal of Research in Family Nursing), 20(2), 117-124.

Nakajima, T., Nagata, K., \& Hirabayashi, K. (2006). Research concerning the practical utility of family evaluations for quality assurance of group homes for the elderly with dementia: Focus on support for the outdoor activitie. Nihon ninchisyou kea gakkaishi (Journal of Japanese Society for Dementia Care), 5(3), 426-435.

Nishiyama, M. (2005). Tomoni kurasu koureisya no ninchisyou hassyou ni tomonau syu-kaigosyano seikatusaihensei (Life Reorganization of Family Caregivers with Getting Dementia of Elders Living with). Rounenkangogaku (Journal of Japan Academy of Gerontological Nursing), 9(2), 85-91.

Ojima, K., \& Kimura, K. (2011). Kaifukuki rihabiriteisyon byoutoukangoshi ga toraeta ninchisyoukoureisya no kazokushien (Family Support of Dementia Elderly provided by Convalescent, Rehabilitation Ward: Discharge Support to the Family who elected for Nursing Care at Home). Herususaiensu kenkyuu (The Japanese Journal of Health Science), 15(1), 55-60.

Omori, E., Kimura, S., Sano, Y., Mine, N., \& Matsumoto, K. (2007). Ninchisyou koureisya wo kakaerukazoku kaigosya no' Tsudoi' heno sanka no imi: Kazokukaigosya no niizu ni tyakumoku shite. (The Significance of "Gatherings" of Family Caregivers of Elderly Dementia Patients: Focusing on the Needs of Family Caregivers). Nihon kangogakkai ronbunsyu: Chiiki kango (Japanese Nursing Association Collection of Papers: Regional Nursing), 37, 240-242.

Ooki, H., Ogata, H., \& Matsuo, Y. (2015). Ninchisyou-kouki-kanjya no eiyou-hokyuu nitsuite dairi-ishikettei wo okonau kazoku heno enjoy (Support for Family in Deputy Decision-making Regarding Nutrition Supply Routes for Late-stage Dementia Patients). Nihon seisinka kango gakkaishi (Journal of the Japanese Psychiatric Nursing Society), 58(1), 220-221.

Soumushyoutoukeikyoku (Statistics Japan). (2014). Statistics Bureau Home Page. from: Statistical Handbook of Japan 2014:. Retrieved December 1, 2016, from http://www.stat.go.jp/english/data/handbook/c0117.htm\#c01

Sugiyama, T., Yuasa, M., \& Takahashi, N. (2009). Ninchisyou koureisya no nyuuin ni tomonau kaigo-kazoku no futankan no henka (Characteristics and the change of family caregiver burden in a ward for the elderly with dementia who has physical complications). Iryou kango kenkyuu (Jounal of Health care and nursing), 5(1), 45-52.

Suzuki, C., Matsuda, N., \& Sakurai, S. (2015). Houmon-kangoshi niyoru ninchisyou-koureisya to kazoku-kaigosya no kankeisei ni chakumoku shita komyunikeesyon kaizen no tameno shien no purosesu (The Relationship-Focused Support Process Offered by Visiting Nurses in Improving Communication between Elderly with Dementia and the Family Caregiver). Nihon zaitakukea gakkaishi (Journal of Japan Academy of Home Care), 19(1).

Tanaka, M., Akagi, Y., Takushima, H., \& Yamaguchi, H. (2007). Ninchisyou-koureisya no kazoku kango ni kansuru kenkyuu: Kazoku kango no 6 dankai no hattenkatei to syakaiteki shien (Study on the Family Nursing Process on Senile Dementia Patients: Six Steps Developmental Process of Family Nursing and Social Support). Hokenkagaku kenkyuushi (Journal of Health Science), 4, 11-19.

Tanaka, T., Fukuhara, K., Shimamoto, A., Takata, A., \& Ikezoe, S. (2012). Ninchisyou kanjya totomoni seikatu suru kazoku no seikatu no aminaoshi (Review of the Lifestyles of Families living with Dementia Patients). Kazoku kango (Family Nursing), 10(2), 142-153.

Tanaka, Y., Ishii, H., \& Matsumoto, Fl. (2011). Needs for special nursing homes for the elderly identified in bereaved families of the residents who died with dementia: Current status of bereaved families who chose to attend the death of a resident in a special nursing home. Igaku to seibutugaku (Medicine and Biology), 155(10), 670-675.

Taniguchi, H. (2003). Kaigoyakuwari no jyuyou to keizoku no katei: kaigoryoutou ni nyuuin shita chihou^koureisya no kazoku kaigosya 2jirei no jirei-kentou wo toosite (The Process of Acceptance and Continuance of Caregiving Roles: Based on a Review of Two Cases of Family Caregivers of Elderly Dementia Patients Hospitalized in Long-term Care Wards). Kokoro no kenkou (The Japanese journal of mental health), 18(2), 41-49.

Watanabe, H., \& Watanabe, K. (2015). Keido-ninchisyou-koureisya tono kakawari no nakade kazoku-kaigosya 
ga idaku kimochi no suii to komyunikeesyon no henka (Changes in the Feelings and Communication of Family Caregivers During their Involvement with Elderly Individuals with Mild Dementia). Kazoku kangogaku kenkyuu (Japanese Journal of Research in Family Nursing), 21(1), 38-49.

Woods, R. T., Keady, J., \& Seddon, D. (2008). Involving Families in Care Homes: A Relationship- Centered Approach to Dementia Care. London: Jessica Kingsley Publishers.

Yamamura, M., Lee, T., \& Kase. (2012). Houm herupaa no ninchisyou riyousya nitaisuru jyouhousyuusyuu no tokusei (Characteristics of information gathering from clients with dementia by home helpers). Kaigofukushigaku (Research Journal of Care and Welfare), 19(2), 147-156.

\section{Copyrights}

Copyright for this article is retained by the author(s), with first publication rights granted to the journal.

This is an open-access article distributed under the terms and conditions of the Creative Commons Attribution license (http://creativecommons.org/licenses/by/4.0/). 